POLSKA AKADEMIA UMIEJĘTNOŚCI

TOM XIII

DARIA JANOWIEC

Uniwersytet Jagielloński

Kraków

\title{
РУССКОЕ ПРАВОСЛАВИЕ В КАТОЛИЧЕСКИХ СМИ НА ПРИМЕРЕ ЖУРНАЛА «GOŚĆ NIEDZIELNY»
}

\author{
THE IMAGE OF THE RUSSIAN ORTHODOX CHURCH \\ IN THE CATHOLIC MEDIA SHOWN BY THE WEEKLY NEWSPAPER \\ THE "GOŚĆ NIEDZIELNY"
}

\begin{abstract}
Streszczenie
Przedmiotem analizy w niniejszym artykule jest obraz rosyjskiego prawosławia w polskiej prasie katolickiej. Zagadnienie to omawiane jest na podstawie najstarszego i najpopularniejszego katolickiego tygodnika, jakim jest „Gość Niedzielny”. Artykuł definiuje termin prasa katolicka oraz omawia pełnione przez nią funkcję. Główna uwaga skupiona jest na prezentacji roli „Gościa Niedzielnego” w kształtowaniu opinii publicznej w odniesieniu do Rosyjskiej Cerkwi Prawosławnej, a także przedstawianiu relacji między Kościołem katolickim i Patriarchatem Moskiewskim oraz wpływu prawosławia na kształtowanie kultury rosyjskiej.
\end{abstract}

\section{Summary}

The subject of this article is an image of the Russian Orthodox Church in Polish Catholic press. The example of most popular and one of the oldest Catholic weekly newspapers the "Sunday Guest" was examined. In the article introduction the definition of a Catholic press and similar conceptions were presented as well as their fundamental functions. Afterward, the role of the "Sunday Guest" in shaping public opinion about the Russian Orthodox Church was considered. The article focuses also on the problems in relations between the Roman Catholic Church and the Russian Ortodox Church and the influence of the Russian Orthodox Chrurch on Russian culture.

Słowa klucze: Rosyjska Cerkiew Prawosławna, Kościół katolicki, prasa katolicka Key words: the Russian Orthodox Church, the Roman Catholic Church, the Catholic press 
Обсуждая тему отношения католической прессы к русскому православию необходимо ответить на вопрос, чем является религиозная пресса. По мнению Чеслава Лехицкого:

«Это пресса, которая остается в области влияния церквей и религиозных общин, ими издана для выполнения идеологических целей религиозного и информационного характера» ${ }^{1}$.

Другой дефиниции придерживается Адам Лепа, который подчеркиват:

«Католическая пресса включает те издания, которые при согласии католической иерархии издаются периодически и распространяются в обществе с целью всестороннего освещения действительности особенно актуальных событий и проблем изжизни Церкви и ее учения»² .

Согласно приведенным дефинициям, информация, которую передает католическая пресса, касается разнообразных сфер жизни, однако явления и события, относящиеся к культуре, политике или экономике должны освящаться с христианской перспективы. Тем, что объединяет всю католическую прессу, является именно система христианских ценностей и миссия распространения христианского мировоззрения. В системе отношений католической Церкви и общества религиозная пресса должна выполнять важнейшую задачу, которой является, с одной стороны, евангелизация, с другой - миссионерство. Святой Престол хорошо понимает роль, которую играют СМИ в современном мире и знает, что их использование дает шанс для передачи взглядов Ватикана широкому кругу людей.

Отвечая на вопрос, почему католическая пресса может сыграть важную роль в формировании представлений общественного мнения в Польше на тему русского православия, стоит привести дефиницию самого термина «общественное мнение». Общественное мнение - это многосторонний процесс коммуникации между людьми, который одновременно охватывает как межличностные отношения, так и соответствующие механизмы деятельности средств массовой информации. Определенная программа, которой следуют СМИ позволяет им более эффективно влиять на общественное мнение. Учитывая этот факт, католическая Церковь уже во второй половине шестидесятых годов в своем социальном учении призывала к формированию правильного общественного мнения при помощи средств масссовой информации ${ }^{3}$.

Исследуя проблемы восприятия русского православия католическими СМИ в Польше, стоит обратить внимание на вопрос развития массмедийного рели-

${ }^{1}$ Cz. Lechicki, Prasa katolicka, w: Encyklopedia wiedzy o prasie, Wrocław 1976, s. 174.

2 A. Lepa, Katalog prasy katolickiej w Polsce, Łódź 1994, s. 4-5.

${ }^{3}$ Inter mirifica. Dekret o środkach spotecznego przekazywania myśli, http://www.kns.gower.pl/ vaticanum/inter.htm, dostęp 02.12.2015. 
гиозного направления в нашей стране в последние 25 лет. За это время католическая Церковь в Польше получила шанс развития и широкого использования средств массовой информации. Главным органом Ватикана, занимающимся передачей информации, является основанное в 1993 году Католическое информационное агентство, которое выпускает печатный бюллетень и редактирует собственный интернет сайт. Оно занимается передачей информации на тему деятельности Святого Престола и внутренней жизни католической Церкви не только в Польше, но и во всем мире. Стоит обратить внимание и на тот факт, что еще в межвоенный период, а точнее в 1935 году, в Польше выходило свыше 300 религиозных журналов ${ }^{4}$. Среди них журналы, принадлежащие пресс концерну, который был создан отцом Максимилианом Марией Кольбе в Непокалянове. Он выпускал журналы «Rycerz Niepokalanej» («Рыцарь Непорочной») с тиражом в 750000 экземпляров и «Mały Rycerz Niepokalanej» («Маленький рыцарь Непорочной») - журнал для детей с тиражом в 221000 экземпляров 5 .

Современная католическая пресса является одним из крупнейших сегментов польского медиарынка. Среди разных католических журналов особенно выделяется еженедельник «Gość Niedzielny». Это самый популярный еженедельник, формирующий общественное мнение в современной Польше. Инициатива его создания приходится на сентябрь 1923 года. С самого начала своего существования данный журнал размещал на своих страницах статьи религиозного характера и религиозно-нравственные рассуждения вместе с информацией о жизни Верхней Силезии, которая являлась главным пространством влияния данного журнала на первом этапе его существования. В 30 - тые годы двадцатого века «Gość Niedzielny» превратился в издание характеризующиеся разнообразной тематикой предназначенной для широкого круга читателей. Его основной целью являлось нравственных и религиозное формирование населения. В кругу общественных проблем чаще всего обсуждаемых в то время на страницах журнала выделялись: алкоголизм, проблемы семьи и священнического призвания. Последний номер этой газеты перед войной вышел 3 сентября 1939 года. Первый послевоенный номер вышел 11 февраля 1945 года. Еженедельник постепенно терял свой местный характер и приобретал более широкий круг читателей. В пятидесятые годы в журнале, в связи с политической ситуацией, преобладали статьи политического характера. Только в половине пятидесятых годов журнал возвращается к своему прежнему направлению. В семидесятые годы «Gość Niedzielny» становится журналом для рабочих и технической интеллигенции. Тогда редакторы решились на сотрудничество со светскими журналистами и преподавателями Католического Университета в Люблине. После

\footnotetext{
${ }^{4}$ A. Paczkowski, Prasa polska w latach 1918-1939, Warszawa 1980, s. 293.

5 W. Zaleski, Święci na każdy dzień, Warszawa 2008, s. 692.
} 
1981 выросло количество репотажей, обсуждались важнейшие события в жизни страны. Больше значения приобретали статьи посвященные общественныым проблемам. Опубликованы были статьи на тему семьи, материалы касающиеся истории Церкви и социального учения Святого Престола, автором которых являлся выдающийся специалист в данной области отец Юзеф Майка. Много места посвящалось проблемам миссионерской деятельности Ватикана. С апреля 1981 года тираж журнала был повышен до 200 000. В конце 80-тых годов «Gość Niedzielny» имел 5 рубрик: богословскую, историческую, общественную, культурную и информационную. В настоящее время в нем 20 разных рубрик. В том числе те, которые касаются политических, экономических, общественных, научных и исторических проблем. В настоящее время тираж журнала это 185 тысяч. Его читателями являются целые семьи.

«Gość Niedzielny» как самый распространенный католический журнал играет значительную роль в формировании восприятия католиками русского православия, понимания католическо-православных отношений, роли и деятельности Русской Православной Церкви в пространстве русской культуры. Данная статья будет посвящена отношениям издания «Gość Niedzielny» к русскому православию со вступления на патриарший престол патриарха Кирилла до избрания папы Франциска.

Стоит подчеркнуть, что большинство комментариев касающихся Русской Православной Церкви не имеют богословского а чисто общественный и даже политический характер. Одним из ведущих авторов данного журнала занимающихся тематикой связанной с Московским Патриархатом является Анджей Граевский - политолог, который с 1981 года сотрудничает с этим журналом являясь главным редактором рубрики «Польша и мир». В ней много места посвящается вопросам русского православия, но их освещение носит сугубо политологический, исторический, социологический или культурологический характер без особенно глубокого освещения богословской тематики.

Информацию периодического издания «Gość Niedzielny» на тему Русской Православной Церкви можно разделить на несколько категорий.

Первой из них являются информации посвященные выдающимся иерархам Русской Православной Церкви и Святого Престола и их взаимоотношениям. Самое большое количество анализов относится к личности патриарха Кирилла. После его выбора журнал представил биографию Его Святейшества подчеркивая при этом неподтвержденные информации об сотрудничестве патриарха с коммунистической властью и тесную связь с митрополитом Никодимом Ротовым Одновременно «Gość Niedzielny» однозначно придерживается мнения, что избрание патриарха Кирилла является новым началом католическо-православных отношений ${ }^{6}$, особенно в связи с его приездом в Польшу.

${ }^{6}$ A. Grajewski, Nowy Patriarcha, stare problemy, http://gosc.pl/doc/802927.Nowy-patriarchastare-problemy, dostęp 02.12.2015 
Другая область интереса журнала «Gość Niedzielny» - освещение событий относящихся к религиозной жизни Русской Православной Церкви. Это прежде всего передача информации о православных праздниках и развитии религиозной жизни в России. Данные статьи пытаются приблизить читателю православный календарь и те события, которые особенно важны для русского православия. В рамках этого круга статей важное место занимают проблемы развития внутриправославного диалога 7 . Однако первостепенную роль среди них играют те, которые приближают читателям еженедельника православную культуру благодаря анализам и биографическим статьям посвященным жизни и деятельности выдающихся православных иерархов, мыслителей и святых. Особенно много места уделяется попыткам понять православную духовность освещая значение личностей таких, как святой Сергий Радонежский ${ }^{8}$. С целью помочь лучше понять русское православие особенно часто освещаются исторически важные для Русской Православной Церкви события как, например, прибытие в Москву Пояса Богородицы. Подчеркивалось огромное количество паломников и многочасовые очереди ожидающих поклониться святым мощам. Анджей Граевский в своих статях обращал внимание на факт, что русские кажутся убежденными в том, что именно возрождение православия является основой для развития страны. По его мнению, высокий показатель тех кто считает себя православными является свидетельством того, что проводимый коммунистической властью эксперимент создания общества без Бога провалился, поскольку не уничтожил полностью связей русского человека с Русской Православной Церковью ${ }^{10}$. Наоборот, после крушения Советского Союза с его господствующей атеистической идеологией пришел бурный рост религиозности населения, среди которого большая группа отождествляет себя с православием и находится в сфере влияния этого вероисповедания.

Очередной группой статей являются те, которые касаются межхристианского диалога. Среди них особенно много места было посвящено проблемам католическо-православных отношений. Жирналисты еженедельника активно освещают именно те события, которые, по их мнению, являются свидетельством притеснения прав католиков на территории России. Эти информации очень часто касаются проблематики передачи имущества принадлежащего католикам в руки православных общин. Комментаторы журнала выражают свое недоволь-

\footnotetext{
${ }^{7}$ A. Macura, Spotkanie dwóch patriarchów, http://gosc.pl/doc/769950.Spotkanie-dwoch-patriarchow, dostęp 02.12.2015

${ }^{8}$ A. Grajewski, Serce Rosji, http://gosc.pl/doc/767182.Serce-Rosji/2, dostęp 02.12.2015

9 J. Malczyk, Pas Maryi nawiedza Rosję, http://gosc.pl/doc/1012854.Pas-Maryi-nawiedza-Rosje, dostęp 02.12.2015

${ }^{10}$ A. Grajewski, Prawosławna Rosja, http://gosc.pl/doc/1326627.Prawoslawna-Rosja, dostęp 02.12 .2015
} 
ство данной ситуацией ${ }^{11}$. С другой стороны в этой группе статей активно осмысляется развитие православия и вытекающих из этого новых перспектив для православно-католического диалога. Благодаря усилению роли Русской Православной Церкви реальным, по мнению журналистов издания «Gość Niedzielny», становится углубление диалога между христианами, в котором особенное место может занять католическая Церковь в Польше. Новое качество польско-русского диалога вытекающее из его нравственного и религиозного основания может сыграть решающую роль в обсуждении болезненных для обоих наций исторических событий. Благодаря тесной связи между православием и католической Церковью в Польше, как утверждают журналисты, возможным становится прекращение многих препятствий. Христианские ценности лежащие в основе культуры обоих народов смогут сблизить католичество и православие в более глобальном смысле. Личности патриарха Кирилла и папы Бенедикта XVI, их взаимоуважение и личные отношения, как утверждали журналисты, становятся одним из важнейших залогов развития католическо-православного диалога $^{12}$. Авторы подчеркивают особенно положительное восприятие деятельности и взглядов папы Бенедикта XVI среди православных в России. В данной группе статей выделяются особенно те, которые касались визита патриарха Кирилла в Польше. При обсуждении всех сложностей связанных с отношением к Русской Православной Церкви в Польше подчеркивалась, прежде всего, защита патриархом христианских ценностей. «Gość Niedzielny» обращает внимание на факт, что Кирилл I является приверженцем единства всей православной общины особенно на канонической территории Московского Патриархата ${ }^{13}$. Журналисты еженедельника особое значение придали визиту патриарха в Польше, который описывался как самое важное историческое событие 2012 года не только в истории католическо-православных отношений, но прежде всего как важное событие русско-польских отношений ${ }^{14}$. Особенно значительной группой статей являлись те, которые касались роли послания о примирении обеих народов, в формирования их взаимоотношений в настоящее время. Событие, которое сосотялось 17 августа 2012 года на протяжении нескольких месяцев было предметом многократного обсуждения. Детально описывался каждый этап подготовки к подписанию документа. В статях посвященных данной теме подчеркивалось не только значение самого события, но прежде всего вовлечение обеих сторон в реализацию

${ }^{11}$ Skandal w Kaliningradzie, http://gosc.pl/doc/772772.Skandal-w-Kaliningradzie, dostęp 02.12.2015

${ }^{12}$ A. Grajewski, Zmiany w Moskwie, http://gosc.pl/doc/788321.Zmiany-w-Moskwie, dostęp 02.12 .2015

${ }^{13}$ Moskwa: Patriarcha apeluje o jedność, http://gosc.pl/doc/912836.Moskwa-Patriarcha-apelujeo-jednosc, dostęp 02.12.2015

${ }_{14}$ B.Łoziński,Rokpolsko-rosyjskiegoorędzia, http://gosc.pl/doc/1406237.Rok-polskorosyjskiegooredzia, dostęp 02.12.2015 
данного проекта. Подробно проанализировано каждый этап работ перед подписанием послания. Подписанный во время этого визита документ о примирении многократно освещался в комментариях журнала. Подчеркивалось, что это был первый в истории католической Церкви в Польше и Русской Православной Церкви совместный документ в тысячелетней истории их соседства, в которой много было недоразумений и прозелитизма ${ }^{15}$. Таким образом, благодаря усилиям журнала, читатели могли лучше понять все сложности самого процесса, но прежде всего лучше познакомиться с русским православием. Стоит обратить внимание на тот факт, что после анализа статей на данную тему можно прийти к выводу, что звеном объединяющим представителей православия и католичества может служить совместная защита христианских ценностей: прав христиан к открытому исповеданию своей веры в любое время, в любом месте, защита права на жизнь нерожденных детей, сопротивление патологическим явлениям таким, как алкоголизм и наркотики, сопротивление по отношению к вооруженным конфликтам и террористическим актам.

«Gość Niedzielny» публикует много статей политологического и исторического характера на тему польско-русских отношений. Важное место в данной группе статей занимают те, которые посвящены событиям в Катыни. Журналисты регулярно возвращаются к данной теме. Проблемы гибели польских офицеров и крушения польского самолета в Смоленске соединяются здесь с тематикой мученической смерти православного духовенства во время правления коммунистического режима. По мнению журналистов, важным знаком положительного отношения Московского Патриархата к ожиданиям поляков является размещение иконы отца Симеона Федоренко - православного каппелана польской армии, убитого в Катыни, в храме Воскресения Христа в Катыни. Икона катынских мучеников в настоящее время расположена на иконостасе этой Церкви. Как подчеркивают журналисты, это свидетельство уважения к полякам погибшим во время репрессий ${ }^{16}$.

Большая группа статей касается общественных проблем современной России и попыток их преодоления со стороны Русской Православной Церкви. Важным направлением деятельности Московского Патриархата освещаемым журналом является благотворительность. Журналисты этого издания очень положительно оценивают работу с нищими и малообеспеченными, в том числе бездомными и беспризорными. Подчеркивают усилия русского православия в области защиты нерожденных детей и решения демографических проблем. 02.12.2015

15 J. Bątkiewicz-Bożek, Wizyta pojednania, http://gosc.pl/doc/1228861. Wizyta-pojednania, dostęp

${ }^{16}$ Polak na ikonie Męczenników Katyńskich, http://gosc.pl/doc/1204726.Polak-na-ikonie-Meczennikow-Katynskich, dostęp 02.12.2015 
Еженедельник пытается последовательно следить за расширением сферы влияния Московского Патриархата на жизнь российского общества.

Как правило освещаются те события, которые характеризуются широким общественным резонансом. В том чиисле вопрос о дорогих часах патриарха или идее создания православного клуба для молодежи. Первостепенную роль занимают те комментарии, которые говорят о роли религии в русском обществе и исторических истоках влияния православия на современное общество ${ }^{17}$. Однако не столько в перспективе его влияния на русскую культуру и государственность, сколько с точки зрения его нравственного авторитета.

Интересной группой статей являются те, которые посвящены проблемам истории православия в России в XX веке. Особенное место занимают комментарии и анализы касающиеся проблемы преследований православных христиан во время правления атеистической власти. Читатели могли познакомиться с биографией и деятельностью архиепископа Серафима Остроумова, который был убить в 1937 году защищая свою веру. Как утверждает журналист Томаш Терликовский, знакомство с подвигом архиепископа Остроумова имеет прямое отношение к проблеме польско-русских отношений, в которых объединяющим звеном может служить верность христианским ценностям и сознание общей истории преследования верующих в обеих странах. По его мнению, это значительно более эффективное средство чем любая деятельность религиозных лидеров или политиков, поскольку данные примеры это открытое свидетельство благодати Господней ${ }^{18}$. Много места посвящено истории Бутова. В статьях на данную тему читатели знакомятся прежде всего с историей этого места, в которым с 1935 по 1937 год было расстреляно свыше 20 тысяч людей ${ }^{19}$.

По мнению еженедельника одной из более серезных проблем Русской Православной Церкви является отсутствие осуждения своего прошлого, в том числе сотрудничества иерархов Московского Патриархата с коммунистической властью. Однако, основной целью является попытка доказать общий исторический опыт русского православия и католической Церкви в Польше.

Богословскую тему, на протяжении проанализированного периода, затрагивают отдельные статьи. Их проблематика связана, прежде всего, с богословием иконы, которое излагается понятным для, не ознакомленного с данной проблематикой читателя, языком.

Важное место, с точки зрения формирования представлений польского читателя о современном русском православии, занимает вопрос о стношениях

${ }^{17}$ Prawosławni o grzechach narodu, http://gosc.pl/doc/852421.Prawoslawni-o-grzechach-narodu, dostęp 02.12.2015

18 T. Terlikowski, Prawosławny męczennik z Katynia, http://gosc.pl/doc/789304.Prawoslawnymeczennik-z-Katynia/2, dostęp 02.12.2015

19 Taize w Moskwie, http://gosc.pl/doc/845581.Taiz-w-Moskwie, dostęp 02.12.2015 
Церкви со светской властью. Журналисты еженедельника ставят вопрос о возможности создания православной политической партии. По их мнению, даже если будет создана партия такого типа ее влияние на политические решения и популярность среди населения не будет очень высока ${ }^{20}$. Способ освещения взаимоотношений светской и духовной власти в России однозначно говорит о том, что, по мнению данного журнала, Русская Православная Церковь вовлечена в политическую жизнь современной России и, более того, она выполняет приказы политических лидеров страны. Еженедельник утверждает, что Московский Патриархат и его иерархы занимаются положительной оценкой решениий президента. Как утверждается в статьях посвященных политической тематике, русское православие только официально и на декларативном уровне отстраняется от открытой поддержки политической силы, а на самом деле оно готово поддержать Кремль. Подтверждением этого, как подчеркивается, является поддержка Владимира Путина во время президентских выборов 2012 года, которая выразилась во встрече патриарха с Владимиром Путиным как одним из кандидатов в президенты ${ }^{21}$. Анализ статей на тему отношений между светской властью и русским православием показывает, что авторы статей негативно оценивают роль православия в развитии политической культуры современной России.

Подытоживая анализ статей журнала «Gość Niedzielny» на тему православия стоит подчеркнуть, что все опубликованные статьи можно разделить на две группы. Первая из них это те, которые касаются критики активности иерархов Московского Патриархата. Одновременно среди именно этой группы статей находятся те, которые говорят о положительной активности Русской Православной Церкви и общих для православия и католичества целях, главной среди которых является защита христианских ценностей. Другая группа относится к развитию православия, его связью с русской культурой. В большинстве случаев статьи касаются проблем политического и общественного характера. Важное место занимают анализы относящиеся к вопросам католическо-православного диалога и роли польских католиков и русских православных в межхритианских отношениях. Несмотря на явно неоднозначный характер статей опубликованных в в периодическом издании «Gość Niedzielny» на тему русского православия голос журнала занимает важное место в процессе формирования представлений о русском православии в польском обществе, о его значении для развития современной культуры России.

${ }^{20}$ Rosja: czy powstanie partia chrześcijańska?, http://gosc.pl/doc/1053527.Rosja-czy-powstaniepartia-chrzescijanska, dostęp 02.12.2015

${ }^{21}$ Rosja: Cerkiewne lansowanie Putina, http://gosc.pl/doc/1076157.Rosja-Cerkiewne-lansowaniePutina, dostęp 02.12.2015 


\section{Bibliografia}

Encyklopedia wiedzy o prasie, pod red. J. Maślanki, Wrocław 1976.

Lepa, A., Katalog prasy katolickiej w Polsce, Łódź 1994.

Łęcicki, G., Media katolickie w III Rzeczpospolitej (1989-2009), „Kultura-media-teologia” nr 2 (2) 2010.

Paczkowski, A., Prasa polska w latach 1918-1939, Warszawa 1980.

Zaleski, W., Święci na każdy dzień, Warszawa 2008.

Pozycje w wersji elektronicznej:

Dziennik Gość Niedzielny, http://gosc.pl/.

Inter mirifica. Dekret o środkach społecznego przekazywania myśli, http://www.kns.gower.pl/ vaticanum/inter.htm, data dostępu: 02.12.2015. 